\title{
PERBANDINGAN TEKNIK RADIOGRAFI CLAVICULA PADA KLINIS FRAKTUR
}

\author{
Ismanto $^{1}$ Vega Melati Putri ${ }^{2}$ \\ 1, 2 ATRO Nusantara, Jakarta \\ Corresponding author: Ismanto \\ Email: faizmanto78@gmail.com
}

\begin{abstract}
Background: The clavicle radiograph is one of the examinations that can diagnose fracture pathology. Radiographic examination of the clavicle generally uses the Antero Posterior (AP) and AP Axial projections $15^{\circ}-30^{\circ}$ cranially. But in fact radiology installations differ in using the position of the patient and the direction of the beam. The purpose of this paper is to determine the radiographic technique of the clavicle in clinical fractures from differences in patient position and beam direction and its effect on the results of the picture.
\end{abstract}

Methods: This type of research is descriptive with a literature study approach, looking for research journals on google scholar, and science direct from November to December 2020, using the keywords clavicle, clavicle, clavicle radiograph, clavicle, clavicle fracture, clavicle x-ray. Of the 15 journals obtained, 4 journals met the criteria.

Results: Examination using 2 projections is only able to provide visualization from a superior and inferior point of view. Examination using 4 projections is able to show viewing angles from anterior, posterior, inferior, and superior. So it can visualize the image better. The 15cranially AP projection is preferred over the $15 \square$ caudally AP projection, because the measurement results are not shortened, and the fracture distance is more visible. No statistically significant difference was found for the difference in arm orientation between arm flexion and arm extension in shortening measurements. The degree of change in the location of the fracture image results in a vertical direction significantly shows greater results when the examination is carried out with the patient in an erect position when compared to the supine patient position.

Conclusions: Based on the projection, the use of 4 projections can eliminate the effect of clavicle fracture distance, and provide a 3-dimensional image. Giving the direction of the beam with an angle above $15 \square$ with a cranially direction produces an optimal picture. In terms of patient position, the optimal image results in the erect position.

Keyword : Radiographic Technique; Invoice; Clavicle; Light Direction

\section{Pendahuluan}

Fraktur adalah rusaknya kontinuitas struktur tulang, dapat diakibatkan oleh kecelakaan, tekanan berulang, atau kelemahan tulang yang abnormal. Berdasarkan data Departemen Kesehatan RI tahun 2018 tercatat sekitar 5,5\% kejadian fraktur di Indonesia dengan $32,7 \%$ pada bagian ekstremitas atas(BPPK, 2018).

Diskontinuitas struktur tulang clavicula menurut United Kingdom, Fraktur clavicula sering disebabkan oleh trauma langsung, yaitu jatuh dengan persentase sebesar 39,6\%. Fraktur clavicula sering terjadi pada pria dewasa muda dan wanita lanjut usia(De Giorgi et.al., 2011). Tipe fraktur clavicula dibagi menjadi tiga, yaitu fraktur distal, medial, proximal clavicula(Donnelly, 2013).

Pemeriksaan radiografi clavicula menurut Bontrager \& Lampignano, (2018) menggunakan proyeksi Antero Posterior (AP) dan AP Axial $15^{\circ}$ $30^{\circ}$ cranially. Sedangkan menurut Long et.al., (2016) teknik radiografi clavicula menggunakan proyeksi AP, AP Axial $0^{\circ}-15^{\circ}$ cranially dengan posisi pasien lordotic, AP Axial $15^{\circ}-30^{\circ}$ cranially, Postero Anterior (PA), PA Axial $15^{\circ}-30^{\circ}$ caudally.

Teknik radiografi clavicula pada kasus fraktur, Austin et al., (2012) telah melakukan perbandingan proyeksi AP dengan arah sinar $0^{\circ}$ dan Axial $20^{\circ}$ cranially dan arah sinar $0^{\circ}$ dan Axial $20^{\circ}$ cranially ditambah $45^{\circ}$ cranially dan $45^{\circ}$ caudally, posisi pasien erect. Hoogervorst et al., (2019) melakukan 
perbandingan proyeksi AP Axial $15^{\circ}$ cranially dan $15^{\circ}$ caudally menggunakan modalitas alat Direct Reconstructed Radiographs (DRRs). Hoogervorst et al., (2020) juga melakukan perbandingan proyeksi AP Axial dengan arah sinar $15^{\circ}$ cranially dan $15^{\circ}$ caudally, dengan posisi pasien erect dan supine. Jonathon et al., (2011) melakukan perbandingan proyeksi AP dan AP Axial $30^{\circ}$ cranially dengan posisi erect dan supine.

Tujuan dari penulisan ini untuk mengetahui teknik radiografi clavicula pada klinis fraktur dari perbedaan posisi pasien dan arah sinar serta efeknya terhadap hasil gambaran.

Faktor eksposi pada pemeriksaan radiografi clavicula menggunakan $81 \mathrm{kVp}$, dengan FFD 100 $\mathrm{cm}$, dan luas lapangan kolimasi $18 \mathrm{~cm} \times 10 \mathrm{~cm}$. Untuk pesawat CR digunakan mAs 10, dosis yang diterima clavicula $0,934 \mathrm{mGy}$. Pada pesawat DR digunakan $\mathrm{mAs} 5$, dosis yang diterima clavicula 0,464 mGy(Long et.al., 2016).

\section{Metode}

Jenis penelitian deskriptif dengan pendekatan studi literatur, mencari jurnal penelitian pada google scholar, dan science direct pada bulan November sampai Desember 2020, menggunakan kata kunci clavicle, clavicula, clavicle radiograph, clavicle, fracture clavicle, clavicle $x$-ray. Dari 15 jurnal yang didapatkan terdapat 7 jurnal tidak lengkap dan 4 jurnal dipublikasikan diluar rentang 10 tahun,sehingga didapatkan 4 jurnal.

\section{Hasil dan Pembahasan}

1. Additional $x$-ray views increase decision to treat clavicular fractures surgically(Austin et al,2012).

Penelitian ini membandingkan hasil gambaran pada pemeriksaan radiografi clavicula dengan menggunakan 2 proyeksi yaitu proyeksi $\mathrm{AP} 0^{\circ}$ dan AP $20^{\circ}$ cranially dan 4 proyeksi yaitu proyeksi AP $0^{\circ}$, AP $20^{\circ}$ cranially, AP $45^{\circ}$ cranially, dan AP $45^{\circ}$ caudally dengan posisi pasien erect. Sampel yang digunakan sebanyak 50 pasien dengan fraktur clavicula tengah

Pemeriksaan dengan menggunakan 2 proyeksi hanya mampu memberikan visualisasi dari sudut pandang superior dan inferior. Pemeriksaan dengan menggunakan 4 proyeksi mampu menunjukkan sudut pandang dari anterior, posterior, inferior, dan superior. Sehingga dapat memvisualisasi gambar lebih baik (lihat gambar1).
Reliabilitas intraobserver yang jauh lebih besar diamati untuk 4 dan 2 proyeksi masing-masing $\left(\mathrm{R}^{1 / 40.76}\right.$ danR $\left.\mathrm{R}^{1 / 40.64}\right)$, tanpa perbedaan dalam reliabilitas interobserver masing-masing (koefisien korelasi intraclass 0.88 dan 0.87).

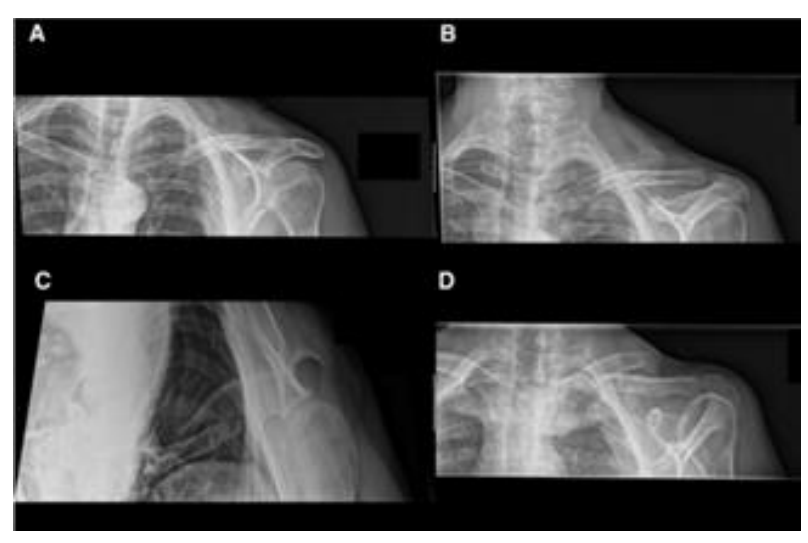

Gambar 1. Radiografi Proyeksi AP $0^{\circ}$ (A), $20^{\circ}$ cranially $(\mathrm{B}), 45^{\circ}$ cranially $(\mathrm{C})$, $45^{\circ}$ caudally(D)

\section{Does altering projection of the fractured clavicle change treatment strategy? (Hoogervorst et al, 2019)}

Membandingkan pemeriksaan radiografi clavicula dengan menggunakan proyeksi AP $15^{\circ}$ cranially dan AP $15^{\circ}$ caudally menggunakan modalitas Digitally Raconstructed Radiographs (DRR). Sampel 36 pasien dengan fraktur clavicula tengah.

Proyeksi AP $15^{\circ}$ cranially lebih banyak dipilih dibandingkan dengan proyeksi AP $15^{\circ}$ caudally, karena hasil pengukuran tidak mengalami shortening, dan jarak fraktur yang lebih terlihat baik (gambar2). Kesepakatan persentase masingmasing adalah 0,66 dan 0,73. berdasarkan koefisien kesepakatan cukup untuk proyeksi AP $15^{\circ}$ cranially (koefisien AC1 Gwet, 0,32; interval kepercayaan 95\%, 0,22-0,42) sedangkan untuk proyeksi AP $15^{\circ}$ caudally (koefisien AC1 Gwet, 0,52 ; interval kepercayaan 95\% , 0,37-0,68). Kesepakatan antar pengamat berbeda secara signifikan antara proyeksi AP $15^{\circ}$ cranially dan proyeksi AP $15^{\circ}$ caudally $(\mathrm{P}=.01){ }^{(12)}$ 


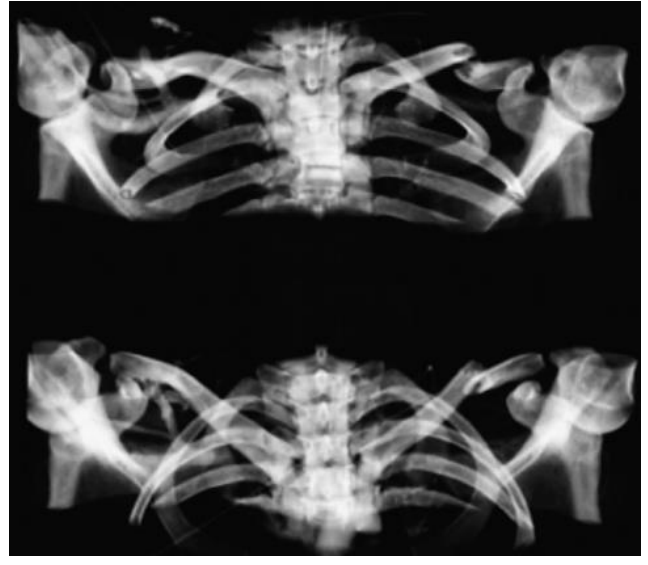

Gambar 2. Radiografi Proyeksi AP $15^{\circ}$ cranially (atas), $15^{\circ}$ caudally (bawah)

3. Influence of radiographic projection and patient positioning on shortening of the fractured clavicle(Hoogervorst et al, 2020)

Membandingkan proyeksi AP $15^{\circ}$ cranially dan $15^{\circ}$ caudally, dengan posisi pasien erect dan supine, posisi objek lengan fleksi (ditekuk) dan ekstensi (lurus). dilakukan pada 22 pasien dengan fraktur clavicula tengah.

Tidak ada perbedaan yang signifikan secara statistik yang ditemukan untuk perbedaan orientasi lengan antara lengan fleksi dan lengan ekstensi dalam pengukuran shortening.

Pada posisi pasien erect hasil pengukuran shortening absolut adalah 4,5 $\mathrm{mm}$ (interval kepercayaan $95 \%$ [CI]: 3,0-5,9, P <.0001) lebih besar daripada pada posisi pasien supine. Untuk derajat perubahan letak hasil gambaran fraktur kearah vertical, kemungkinan mendapat skor kategori lebih tinggi pada posisi pasien erect adalah 4,7 (95\% CI: 2,2-9,8) kali lebih besar dari jika dibandingkan dengan posisi supine. Pemeriksaan dengan proyeksi AP $15^{\circ}$ cranially mendapat skor lebih tinggi 5,9 (95\% CI: 2,8-12,6) kali lebih besar jika dibandingkan dengan proyeksi AP $15^{\circ}$ caudally. Absolute shortening, relative shortening, dan derajat perubahan letak hasil gambaran fraktur kearah vertical ditemukan mendapatkan hasil yang terbaik dalam posisi pasien erect dengan orientasi lengan fleksi pada proyeksi AP $15^{\circ}$ cranially $^{(13)}$.

\section{Upright vs. Supine Radiographs of Clavicle Fractures: Does Positioning Matter? (Backus et al, 2014)}

Membandingkan proyeksi $\mathrm{AP} 0^{\circ}$ dan $\mathrm{AP} 30^{\circ}$ cranially dengan posisi pasien supine dan erect. dilakukan pada 46 pasien dengan fraktur clavicula tengah.

Derajat perubahan letak hasil gambaran fraktur kearah vertical secara signifikan menunjukkan hasil yang lebih besar pada saat pemeriksaan dilakukan dengan posisi pasien erect jika dibandingkan dengan posisi pasien supine ( $\mathrm{p}$ $<0,001)$. Gambaran radiografi dengan posisi supine memiliki sudut pandang rata-rata $8,4 \pm 6,6 \mathrm{~mm}$ sedangkan radiografi dengan posisi pasien erect memiliki sudut pandang rata-rata 15,9 $\pm 8,9 \mathrm{~mm}$. Sudut pandang meningkat rata-rata $7,5 \mathrm{~mm}(89 \%)$ pada film tegak jika dibandingkan dengan radiografi supine. Sebanyak 44\% (20/46) pasien memiliki sudut pandang lebih dari $100 \%$ pada posisi erect, tetapi tidak pada radiografi pada posisi supine. Jika sudut pandang pada kasus fraktur clavicula tengah yang diukur pada radiografi dengan posisi erect rata-rata $(17,1 \pm 7,9 \mathrm{~mm})$ dibandingkan dengan sudut pandang yang diukur pada radiografi dengan posisi supine $(9,0 \pm 6,0$ $\mathrm{mm}$ ) diperoleh hasil $\mathrm{p}<0,001$. $^{(14)}$

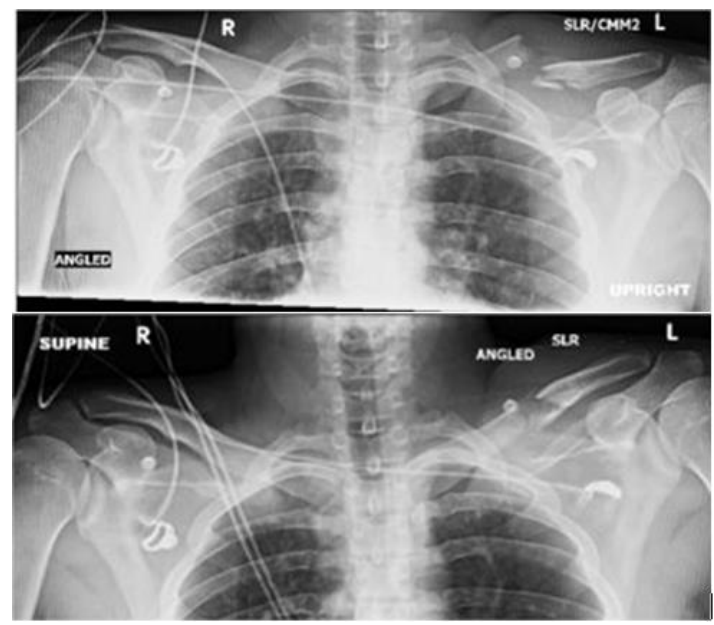

Gambar 3. Posisi Erect (atas), Posisi Supine (bawah)

\section{Posisi Pasien}

Posisi pasien erect memiliki hasil dari pengukuran shortening yang lebih besar daripada posisi pasien supine.

Pemeriksaan dengan posisi pasien erect mampu menampilkan derajat perubahan letak hasil gambaran fraktur yang lebih besar jika dibandingkan dengan posisi pasien supine. sudut pandang pada kasus fraktur clavicula tengah yang diukur pada radiografi dengan posisi erect rata-rata $(17,1 \pm 7,9 \mathrm{~mm})$ dibandingkan dengan sudut 
pandang yang diukur pada radiografi dengan posisi supine.

Derajat perubahan letak hasil gambaran fraktur kearah vertical ditemukan mendapatkan hasil yang terbaik dalam posisi pasien erect dengan orientasi lengan fleksi pada proyeksi AP $15^{\circ}$ cranially.

\section{Arah Sinar}

Penggunaan arah sinar yang banyak dari $0-45$ derajat lebih baik karena dapat memperlihatkan objek dari anterior, posterior, inferior, dan superior.

Arah sinar cranially lebih memperlihatkan objek fraktur tanpa superimposisi tulang calvicula dibandingkan dengan arah sinar caudally

Perbandingan pada pemeriksaan dengan proyeksi AP $15^{\circ}$ cranially dan $15^{\circ}$ caudally yang dilakukan, secara statistik hanya memberikan perbedaan kecil, kemungkinan menggunakan penyudutan yang lebih besar akan memberikan perbedaan yang lebih signifikan secara klinis untuk dapat diidentifikasi.

\section{Simpulan}

Berdasarkan proyeksi, penggunaan 4 proyeksi mampu menghilangkan efek jarak fraktur clavicula, dan memberikan gambaran 3 dimensi. Pemberian arah sinar dengan penyudutan diatas $15^{\circ}$ dengan arah cranially menghasilkan gambaran yang optimal. Dari segi posisi pasien, hasil gambar yang optimal dalam posisi erect.

\section{Daftar Pustaka}

World Health Organization. The World Health Report [Internet]. 2010 [cited 2021 Feb 3]. Available from: World Health Organization. The World Health Report [Internet]. 2010 [cited $2021 \mathrm{Feb}$ 3]. Available from: http://www.who.int./whr/2010/en/index.htmlD e Giorgi S, Notarnicola A, Tafuri $S$ et al. Conservative treatment of fractures of the clavicle [Internet]. 2011. Available from: https://bmcresnotes.biomedcentral.com/articles /10.1186/1756-0500-4-333

Donnelly TD, MacFarlane RJ, Nagy MT, Ralte P, Waseem M. Fractures of the Clavicle: An Overview. Open Orthop J. 2013;7(1):329-33.

Bontrager KL, Lampignano J. Textbook of radiographic positioning and related Anatomy. Elsevier Health Sciences; 2018.

Long BW, SMITH BJ, ROLLIN JH. Radiography Positiong \& Prosedur. 2016. 606 p.
Austin LS, O'Brien MJ, Zmistowski B, Ricchetti ET, Kraeutler MJ, Joshi A, et al. Additional x-ray views increase decision to treat clavicular fractures surgically. J Shoulder Elb Surg [Internet]. 2012;21(10):1263-8. Available from: http://dx.doi.org/10.1016/j.jse.2011.08.050

Hoogervorst P, Appalsamy A, Meijer D, Doornberg JN, van Kampen A, Hannink G. Does altering projection of the fractured clavicle change treatment strategy? J Shoulder Elb Surg [Internet]. 2019;28(3):e65-70. Available from: https://doi.org/10.1016/j.jse.2018.08.008

Hoogervorst P, van Geene A, Gundlach U, Wei A, Verdonschot N, Hannink G. Influence of radiographic projection and patient positioning on shortening of the fractured clavicle. JSES Int [Internet]. 2020;4(3):503-7. Available from: https://doi.org/10.1016/j.jseint.2020.03.005

Jonathon D, Backus M, David J Merriman M, Christopher M McAndrew M, Michael J Gardner M, William M Ricci M. NIH Public Access. Bone. 2011;23(1):1-7. 